\title{
Non-variceal Upper Gastro-intestinal Bleeding in Patients of Liver Cirrhosis
}

MUHAMMAD SHAHID NAWAZ KHAN ${ }^{1}$, HAFIZ YASIR QAMAR ${ }^{2}$, MUHAMMAD FAROOQ KHAN ${ }^{3}$, ABEERA ABDUL GHAFFAR $^{4}$, FARAH SATTAR ${ }^{5}$

${ }^{1}$ Associate Professor Medicine, Nishtar Hospital Multan.

${ }^{2}$ PGR Medicine, Nishtar Hospital Multan.

${ }^{3}$ Medical Officer, Government Shahbaz Sharif Hospital Multan.

${ }^{4} \mathrm{PGR}$ Radiology, Combined Military Hospital Multan.

${ }^{5}$ Senior Registrar Dermatology, Nishtar Hospital Multan

Correspondence to Dr. Hafiz Yasir Qamar, Email: yasirqamar222@gmail.com, Mobile +92 3356344400

\begin{abstract}
Aim: To determine the frequency of non-variceal upper gastro-intestinal bleeding (NVUGIB) in patients of liver cirrhosis.

Methods: A total number of 136 patients of liver cirrhosis having upper Gl bleeding who presented in medical emergency of Nishtar Hospital Multan were included in this cross-sectional analysis. Gastric Endoscopy was done all patients to determine the presence of NVUGIB in all patients. Data regarding patient's age, Body mass index (BMI), gender and duration of upper $\mathrm{Gl}$ bleed was also collected.

Results: Mean age was $47.23 \pm 9.45$ years. Mean body mass index (BMI) was $24.94 \pm 3.35 \mathrm{~kg} / \mathrm{m}^{2}$. Mean duration of upper UGIB was $3.45 \pm 3.03$ months. There were $94(69.12 \%)$ male and $42(30.88 \%)$ female patients. NVUGIB was found in 76(55.88\%). There was a significant association of age with NVUGIB. In patients of age 20-49 years, NVUGIB was found in 47(62.7\%) patients. In having age 49-65 years, NVUGIB was found in $29(47.5 \%)$ patients.

Conclusion: NVUGIB in patients with liver cirrhosis is very common and it is more common in younger age patients. So diagnostic endoscopy should be done in liver cirrhosis patients presenting with upper Gl bleeding in emergency departments. This will aid in proper diagnosis and in deciding the appropriate treatment in these patients.
\end{abstract}

Keywords: Non-variceal upper gastro-intestinal bleeding, liver cirrhosis, Hepatitis.

\section{INTRODUCTION}

Upper gastrointestinal bleeding (UGIB) is a common medical emergency accounting for $70 \%$ of the cases presenting with acute visceral bleeding, while the remaining $30 \%$ cases have non-visceral cause. ${ }^{1}$ UGIB accounts for a total of $8 \%$ hospital admissions. The prevalence rate of UGIB is 50 to $150 / 100,000$ people in USA and 100 to $107 / 100,000$ per year in UK. ${ }^{2}$ UGIB is associated with significant mortality rate ranging from 4 to $15 \% \%^{3,4}$.

UGIB is defined as a bleeding disorder whose origin is above the level of Treitz ligament. ${ }^{5}$ The common presentation in these patients is melena occurring in $70 \%$ to $80 \%$ cases and hematemesis occurring in $40 \%$ to $50 \%$ cases. ${ }^{6}$ Hematochezia is a rare presentation and in majority of these cases the source is usually the lower Gl bleeding ${ }^{6}$ The occurrence rate of gatro-esophageal varices is about $7 \%$ year ${ }^{7}$. Varices occur in about $12 \%$ of the patients of liver cirrhosis each year with $5 \%$ patients developing small varices and up-to $7 \%$ large varices. ${ }^{8}$ Up-to 30 to $40 \%$ patients with UGIB have non-visceral cause frequently caused by gastric ulcers, portal gastropathy, Mallory-Weiss tears and duodenal erosions ${ }^{9}$.

In this study we determined the frequency of nonvariceal upper gastro-intestinal bleeding (NVUGIB) in patients of liver cirrhosis. As there is a difference in the management of variceal versus non-variceal UGI bleeding

Received on 25-02-2021

Accepted on 05-05-2021 in liver cirrhosis patients. So determining the frequency of NVUGIB can help to decide empirical treatment in patients of liver cirrhosis presenting with UGIB.

\section{METHODS}

In this descriptive cross-sectional study, we included 136 patients of liver cirrhosis of age 20 to 65 who presented in the medical emergency of Nishtar Hospital Multan from June-2020 to Feb-2021 with suspicion of UGIB (such as hematemesis or melena) were included. Patients who presented with UGIB without evidence of liver cirrhosis were excluded. Approval of study was obtained from ERC of hospital.

After admission, gastric Endoscopy was done in all patients to determine the presence of NVUGIB in all patients.Presence of bleeding proximal to the ligament of Treitz along with presence of normal mucosal wall of esophagus, gastric or duodenum on endoscopy was labelled as NVUGIB.

Data was analyzed using SPSS v23. Frequency and percentage were used to present gender, and presence of NVUGIB. While age, BMI and duration of upper GI bleed were presented as mean \pm standard deviation. Chi-square test was applied to determine the association of age and gender with NVUGIB, taking $p$-value $\leq 0.05$ as significant.

\section{RESULTS}

Mean age of patients was $47.23 \pm 9.45$ years. Minimum BMI was $18.40 \mathrm{~kg} / \mathrm{m}^{2}$ and maximum $\mathrm{BMl}$ was 34.70 
$\mathrm{kg} / \mathrm{m}^{2}$. Mean duration of upper GIB was $3.45 \pm 3.03$ months. There were $94(69.12 \%)$ male and $42(30.88 \%)$ female patients (Figure 1). NVUGIB was found in 76(55.88\%) patients (Figure 2).

There was a significant association of age with NVUGIB. In patients of age 20-49 years, NVUGIB was found in $47(62.7 \%)$ patients. In having age 49-65 years, NVUGIB was found in 29 (47.5\%) patients. However, the pvalue did not reach to significant association ( $p$-value 0.07 ). There was also no association of gender with NVUGIB. In male patients, NVUGIB was found in 54(57.4\%) Male patients and in $22(52.4 \%)$ male patients ( $p$-value 0.583 ) (Table 1).

Figure 1.Frequency of Gender.

\section{Gender}

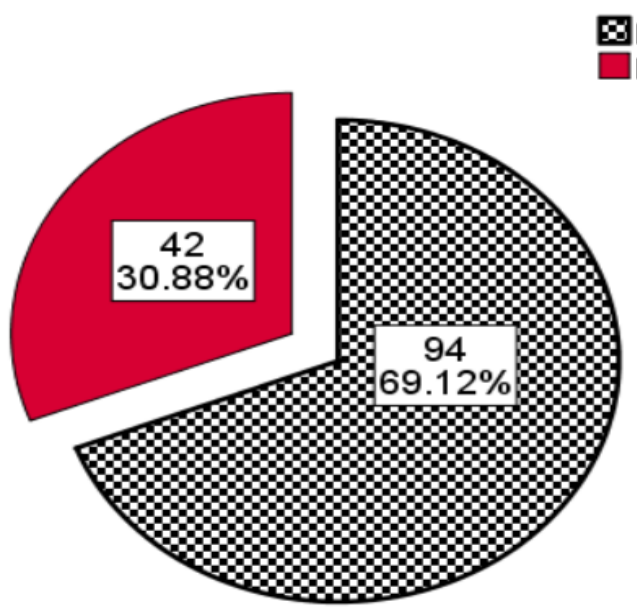

Figure 2.Frequency of Non-Variceal Upper GI Bleeding.

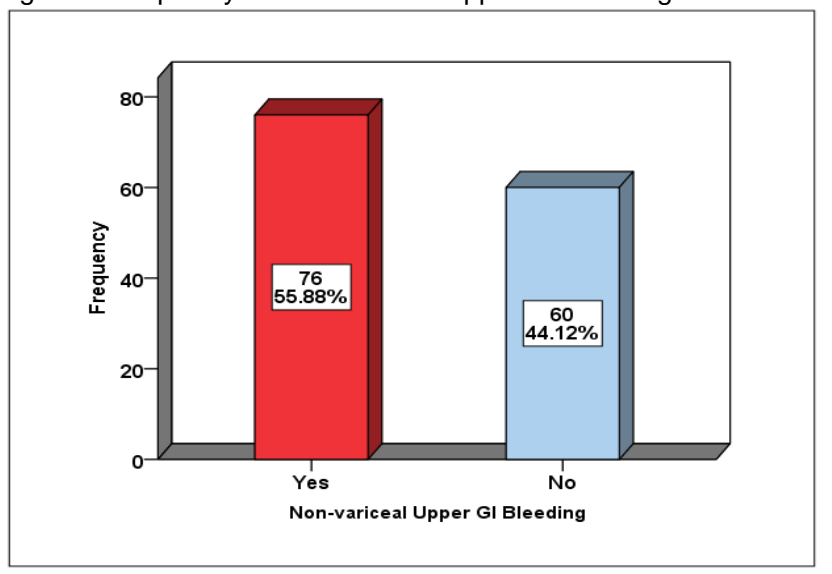

Table 1: Association of Age and Gender with NVUGIB.

\begin{tabular}{|l|c|c|c|}
\hline \multirow{2}{*}{ Age Group } & \multicolumn{2}{|c|}{ NVUGIB } & \multirow{2}{*}{ P-value } \\
\cline { 2 - 3 } & Yes & No & \\
\hline $20-49$ Years & $47(62.7 \%)$ & $28(37.2 \%)$ & \multirow{2}{*}{0.07} \\
\hline $51-65$ Years & $29(47.5 \%)$ & $32(52.5 \%)$ & \\
\hline Gender & $54(57.4 \%)$ & $40(42.6 \%)$ & \multirow{2}{|l|}{0.583} \\
\hline Male & $22(52.4 \%)$ & $20(47.6 \%)$ & 0.583 \\
\hline Female &
\end{tabular}

\section{DISCUSSION}

NVUGIB is a routine presentation in the emergency gastroenterology units and is a challenging condition. The annual reported incidence 50 to 150 people per 100,000 people. Despite improvements in endoscopic techniques and supportive care the mortality of NVUGIB remains high even some reports have reported mortality in up-to 35\% patients. Incidence is high in old age patients and it occurs in up-to $25 \%$ patients of age $>80$ years and majority of these bleedings occur during hospital stat and is associated with poor prognosis of these patients ${ }^{10,11}$.

Association of UGIB in cirrhosis patients is not widely studied and existing guidelines such European and American regarding UGIB have not separated UGIB patients of cirrhosis and non-cirrhosis patients and have reported separate epidemiological profile of these patients. ${ }^{12-14}$ However, some authors have investigated this association and reported poor prognosis and higher mortality in patients of UGIB having liver cirrhosis by using multivariate analysis and prediction models ${ }^{15}$.

Mean age in present study was $47.23 \pm 9.45$ years and there were $69.12 \%$ male and $30.88 \%$ female patients. Pasha et al.reported mean age $47.46 \pm 11.79$ years. In their study, there were $56 \%$ male and $44 \%$ female patients. ${ }^{16}$

In our study, NVUGIBwas found in $55.88 \%$ patients on endoscopic examination. In González-González et al. trialcontaining a large population of 2217 patients of UGIB, reported NVUGIB in $48.7 \%$ patients of liver cirrhosis ${ }^{17}$.

A study conducted by Seo et al. reported NVUGIB in $77.7 \%$ of cirrhotic patients ${ }^{18}$.

While another study by Gabr et al. including 550 patients of liver cirrhosis who presented with UGIB,reported NVUGIB in only $24.5 \%$ patients of liver cirrhosis ${ }^{10}$.

A study conducted in Pakistan by Mobin et al on 267 patients of UGIB having liver cirrhosisreported NVUGIB in $56.93 \%$ patients $^{19}$.

The single limitation of this research is that we included data only from a single centre. Moreover, we did not collected data of therapeutic interventions being performed in these patients.

According to present findings, a thorough investigation should be performed in cirrhotic patients who present with UGIB for esophageal and gastric varices and source of bleeding should also be searched in stomach and duodenum during endoscopy.

\section{CONCLUSION}

NVUGIB in patients with liver cirrhosis is very common and it is more common in younger age patients. So diagnostic endoscopy should be done in liver cirrhosis patients presenting with upper $\mathrm{Gl}$ bleeding in emergency departments. This will aid in proper diagnosis and in deciding the appropriate treatment in these patients.

\section{REFERENCES}

1. Rudler M, Rousseau G, Benosman H, Massard J, Deforges L, Lebray $\mathrm{P}$, et al. Peptic ulcer bleeding in patients with or without cirrhosis: different diseases but the same prognosis? Aliment Pharmacol Ther. 2012;36(2):166-72. 
2. Hadayat R, Gul R, Khan AN, Said K, Gandapur A Endoscopic findings of upper gastrointestinal bleeding in patients with liver cirrosis. Journal of Ayub Medical College Abbottabad. 2015;27(2):391-4.

3. Schmidt ML, Barritt AS, Orman ES, Hayashi PH. Decreasing mortality among patients hospitalized with cirrhosis in the United States from 2002 through 2010. Gastroenterology. 2015;148(5):967-77.e2.

4. Vergara $M$, Clèries $M$, Vela $E$, Bustins $M$, Miquel $M$, Campo R. Hospital mortality over time in patients with specific complications of cirrhosis. Liver international : official journal of the International Association for the Study of the Liver. 2013;33(6):828-33.

5. Biecker E. Diagnosis and therapy of non-variceal upper gastrointestinal bleeding. World J Gastrointest Pharmacol Ther. 2015;6(4):172-82.

6. Rotondano G. Epidemiology and diagnosis of acute nonvariceal upper gastrointestinal bleeding. Gastroenterol Clin North Am. 2014;43(4):643-63.

7. Karadsheh $\mathrm{Z}$, Allison $\mathrm{H}$. Primary prevention of variceal bleeding: pharmacological therapy versus endoscopic banding. N Am J Med Sci. 2013;5(10):573-9.

8. Mantovani A, Tsochatzis EA. Epidemiology of Varices and Variceal Bleeding in Liver Cirrhosis. Variceal Bleeding in Liver Cirrhosis: Springer; 2021. p. 1-11.

9. Peng Y, Qi X, Dai J, Li H, Guo X. Child-Pugh versus MELD score for predicting the in-hospital mortality of acute upper gastrointestinal bleeding in liver cirrhosis. Int J Clin Exp Med. 2015;8(1):751-7.

10. Gabr MA, Tawfik MA, El-Sawy AA. Non-variceal upper gastrointestinal bleeding in cirrhotic patients in Nile Delta. Indian J Gastroenterol. 2016;35(1):25-32.

11. Sengupta N, Feuerstein JD, Patwardhan VR, Tapper EB, Ketwaroo GA, Thaker AM, et al. The risks of thromboembolism vs. recurrent gastrointestinal bleeding after interruption of systemic anticoagulation in hospitalized inpatients with gastrointestinal bleeding: a prospective study. Am J Gastroenterol. 2015;110(2):328-35.

12. Rockall TA, Logan RF, Devlin HB, Northfield TC. Incidence of and mortality from acute upper gastrointestinal haemorrhage in the United Kingdom. Steering Committee and members of the National Audit of Acute Upper Gastrointestinal Haemorrhage. BMJ. 1995;311(6999):222-6.

13. Czernichow $P$, Hochain $P$, Nousbaum JB, Raymond JM, Rudelli A, Dupas JL, et al. Epidemiology and course of acute upper gastro-intestinal haemorrhage in four French geographical areas. Eur J Gastroenterol Hepatol. 2000;12(2):175-81.

14. Hopper AD, Sanders DS. Upper GI bleeding requires prompt investigation. Practitioner. 2011;255(1742):15-9, 2.

15. Kuo MT, Yang SC, Lu LS, Hsu CN, Kuo YH, Kuo CH, et al Predicting risk factors for rebleeding, infections, mortality following peptic ulcer bleeding in patients with cirrhosis and the impact of antibiotics prophylaxis at different clinical stages of the disease. BMC Gastroenterol. 2015;15:61.

16. Pasha MB, Hashir MM, Pasha AK, Pasha MB, Raza AA, Fatima M. Frequency of esophageal varices in patients with upper gastrointestinal bleeding. 2011.

17. González-González JA, García-Compean D, VázquezElizondo G, Garza-Galindo A, Jáquez-Quintana JO, Maldonado-Garza H. Nonvariceal upper gastrointestinal bleeding in patients with liver cirrhosis. Clinical features, outcomes and predictors of in-hospital mortality. A prospective study. Ann Hepatol. 2011;10(3):287-95.

18. Seo YS, Kim YH, Ahn SH, Yu SK, Baik SK, Choi SK, et al. Clinical features and treatment outcomes of upper gastrointestinal bleeding in patients with cirrhosis. J Korean Med Sci. 2008;23(4):635-43.

19. Mobin A, Qureshi F, Kumar D, Haroon $H$, Jabeen $R$ CHRONIC LIVER DISEASE. The professional Medical Journal. 2016;23(02):204-8 